\title{
microorganisms
}

www.mdpi.com/journal/microorganisms

Article

\section{Comparison of Microbiological and Probiotic Characteristics of Lactobacilli Isolates from Dairy Food Products and Animal Rumen Contents}

\author{
Neethu Maria Jose ${ }^{1}$, Craig R. Bunt ${ }^{2}$ and Malik Altaf Hussain ${ }^{1, *}$ \\ 1 Department of Wine, Food and Molecular Biosciences, Lincoln University, Lincoln 7647, \\ New Zealand; E-Mail: neethumaria@rocketmail.com \\ 2 Department of Agriculture, Lincoln University, Lincoln 7647, New Zealand; \\ E-Mail: craig.bunt@lincoln.ac.nz \\ * Author to whom correspondence should be addressed; E-Mail: malik.hussain@lincoln.ac.nz; \\ Tel.: +64-3-4230-638.
}

Academic Editor: Giuseppe Comi

Received: 9 March 2015 / Accepted: 25 March 2015 / Published: 15 April 2015

\begin{abstract}
Lactobacilli are employed in probiotic food preparations and as feed additives in poultry and livestock, due to health benefits associated with their consumption. The objective of this study was to evaluate and compare the probiotic potential of ten lactobacilli strains isolated from commercial dairy food products and animal rumen contents in New Zealand. Genetic identification of the isolates revealed that all belonged to the genus Lactobacillus, specifically the species L. reuteri, L. rhamnosus and L. plantarum. All isolates did not show any haemolytic behaviour. Isolates of dairy origin showed better tolerance to low $\mathrm{pH}$ stress. On the other hand, rumen isolates exhibited a higher tolerance to presence of bile salts. All isolates exhibited resistance to aminoglycoside antibiotics, however most were sensitive to ampicillin. Isolates of rumen origin demonstrated a higher inhibitory effect on Listeria monocytogenes, Enterobacter aerogenes and Salmonella menston. Bacterial adherence of all isolates increased with a decrease in $\mathrm{pH}$. This screening study on lactobacilli isolates has assessed and identified potential probiotic candidates for further evaluation.
\end{abstract}

Keywords: lactobacilli; dairy food; animal rumen; screening; comparing in vitro characteristics 


\section{Introduction}

It has recently been reported that global probiotics demand was worth USD 27.9 billion in 2011 and is expected to reach USD 44.9 billion in 2018 [1]. The global market for probiotics is mainly driven by high demand for probiotic yoghurt and growing consumption of functional foods. This report identified growing consumer awareness regarding gut health having played a key role in sustaining this market.

Lactobacilli form the major group of bacteria incorporated into foods for use as probiotics or functional foods. Amongst the lactic-acid producing group, species of Lactobacillus, Bifidobacterium and Enterococcus, such as L. acidophilus, L. casei, L. reuteri, L. rhamnosus, L. lactis, L. crispatus, L. gasseri, B. animalis, B. bifidum, B. infantis, B. lactis, E. faecalis, and E. faecium, are prevalent [2,3]. The non-lactic acid producers include Bacillus cereus and B. subtilis. In addition, yeast such as Saccharomyces boulardii and S. cerevisiae are also used as probiotics [4-6]. Probiotics are commercially available in the form of powder, liquid, gel, paste, granules or even as capsules, sachets, etc. [7,8]. To observe a positive health benefit from consumption, a minimum level of microorganisms is required: this level depends on the strain used and the required health benefit. The dose recommended is usually between $10^{9}$ and $10^{11} \mathrm{CFU} /$ day [9].

An effective probiotic is expected to function and survive under a variety of physiological conditions. Screening factors for probiotic abilities, carried out in this study, were based on the following assumptions. Upon consumption, probiotic bacteria should survive transit in the gastro-intestinal tract where it is open to challenges, such as the low $\mathrm{pH}$ environment of stomach and bile salts of the upper intestinal tract [10-13]. Stomach $\mathrm{pH}$ can vary from as low as 1-2 under fasting conditions and up to 4-5 following ingestion of a meal [14,15]. Probiotics must also be safe, for example probiotic bacteria should not cause lysis of red blood cells. Furthermore, antibiotic resistance may be necessary for survival in the presence of co-administered drugs [9]. The genes conferring resistance in probiotics should be innate in nature and non-transferable to other bacteria [16]. Display of antimicrobial activity against common intestinal pathogens is also highly preferred [11]. A common mechanism of lactobacilli to achieve these activities towards pathogens is by the production of organic acids, which lowers the $\mathrm{pH}$, thereby creating a hostile environment for the growth of other bacteria. Simultaneously, these organic acids can prove toxic to other bacteria, thereby inhibiting pathogen growth. Competitive inhibition for mucosal binding sites between pathogen and probiotic bacteria also limits the growth and colonization of pathogens in the body [17]. Probiotic bacteria must also be capable of adhering to intestinal epithelial lining in order to provide benefits in the host. Adherence enables the probiotic bacteria to persist for a longer time in the gut and enhances the host-bacteria interactions [18]. Adherence of probiotic bacteria also helps it to overcome peristalsis activity of stomach [19]. For this purpose, their surface properties were studied by performing the BATH (Bacterial Adherence to Hydrocarbons) test.

This study was undertaken to characterize and draw a comparison of potential probiotic characteristics of dairy versus rumen isolates. Dairy isolates are capable of growing in the food processing conditions whereas rumen isolates are well adapted to grow in the gastro-intestinal tract (GIT) environment. The objective was to see the performance characteristics exhibited by lactobacilli isolated from two diverse environments and make a comparison of their potential probiotic properties. There have been previous papers describing screening characteristics of potential probiotic lactobacilli from diverse sources such as traditional dairy food, swine origin, cheese, infant gut 
micro-biota, etc. [20-23]. However, this is perhaps the first study reporting a comparison of in vitro characteristics of strains isolated from commercial foods and environmental sources from New Zealand.

\section{Experimental Section}

\subsection{Isolation, Phenotypic Characterization and Carbohydrate Fermentation Profile of Strains}

The lactic acid bacteria (LAB) isolates used in this study were isolated from two different sources-commercial dairy food products and animal rumen contents in New Zealand. Dairy food products included yoghurt and two different types of cheeses. Rumen contents used in this study were obtained from cow. For all the four samples, $10 \mathrm{~g}$ or $10 \mathrm{~mL}$ of sample was added to $40 \mathrm{~mL}$ of de Man, Rogosa, Sharpe (MRS) broth (Oxoid, Basingstoke, UK) and homogenized by vortex mixing. The inoculated broth samples were incubated at $37^{\circ} \mathrm{C}$ for $24 \mathrm{~h}$ under anaerobic conditions. Tubes showing turbidity were selected and inoculated onto MRS agar plates. Cultures were purified by re-streaking on MRS agar 2-3 times. The isolates were stored in $50 \%$ glycerol at $-20{ }^{\circ} \mathrm{C}$ until further use.

The cultures were characterized as LAB by gram-staining and microscopic observation (using Nikon Eclipse 50i). Also colony morphology was studied by growing cultures on MRS agar plates. Oxidase activity was identified using oxidase colour indicating strips (Oxoid Microbact ${ }^{\mathrm{TM}}$ Identification kit, UK). Carbohydrate fermentation profiles of the isolates were generated according to the method described by Gupta et al. [24]. Sugars used to generate fermentation profiles included arabinose, cellobiose, fructose, glucose, galactose, lactose, mannose, mannitol, melibiose, maltose, raffinose, ribose, sorbitol and sucrose. Glycerol was used as a negative control.

\subsection{Identification of $L A B$}

DNA of the ten isolates was extracted using Gentra Puregene cell kit. Polymerase Chain Reaction (PCR) analysis of 16S-23S rRNA gene (intergenic spacer region) of Lactobacillus isolates using primers 5'-GAATCGCTAGTAATCG-3' and 3'-GGGTTCCCCCATTCGGA-5' was performed followed by agarose gel electrophoresis. Amplified PCR products were sequenced by the Bio-Protection Research Centre (Christchurch, New Zealand). The sequences obtained were analysed using the nucleotide blast program provided by the online Basic Local Alignment Search Tool (BLAST ${ }^{\circledR}$ ), a database search tool, developed and maintained by the National Center for Biotechnology Information (NCBI) available online at http://blast.ncbi.nlm.nih.gov/Blast.cgi.

\subsection{Acid Tolerance}

Overnight cultures of lactobacilli strains were added to MRS broth adjusted to $\mathrm{pH} 2$ and $\mathrm{pH} 3$, with $1 \mathrm{M} \mathrm{HCl}$. The initial bacterial concentration was $10^{6} \mathrm{CFU} / \mathrm{mL}$. The broths were incubated for $6 \mathrm{~h}$ and cell viability was determined by serial dilution and plating onto MRS agar after 0,3 and $6 \mathrm{~h}$ incubation. 


\subsection{Bile Salt Tolerance}

To determine bile salt tolerance strains were grown overnight in MRS broth. Sufficient cell suspension to give $10^{6} \mathrm{CFU} / \mathrm{mL}$ concentration of each isolate was added into $10 \mathrm{~mL}$ of fresh MRS media containing $0.3 \%$ and $2 \%$ of bile salts (Oxoid, UK). The broths were incubated for $6 \mathrm{~h}$ and cell viability was determined by serial dilution and plating onto MRS agar after 0,3 and $6 \mathrm{~h}$ incubation.

\subsection{Haemolytic Activity}

Haemolytic activity of LAB strains was determined according to the method described by Maragkoudakis et al. [25] with slight modification. The isolates were grown overnight in MRS broth and then streaked onto Columbia blood agar plates (Fort Richard, Auckland, New Zealand), containing $5 \%$ sheep blood. The plates were incubated at $37{ }^{\circ} \mathrm{C}$ for $24 \mathrm{~h}$ in anaerobic jars. The strains were characterized as haemolytic, partial haemolytic or non-haemolytic depending on the colour change of the agar underlying the colonies. Listeria monocytogenes and Salmonella menston were used as positive controls. The assay was performed in triplicate.

\subsection{Antibiotic Resistance}

Antibiotic susceptibility was determined by the disc diffusion method. The procedure was adapted from Thirabunyanon et al. [26]. Antibiotics tested included (i) inhibitors of bacterial cell wall synthesis: ampicillin $10 \mu \mathrm{g}$, amoxicillin $30 \mu \mathrm{g}$, vancomycin $30 \mu \mathrm{g}$; (ii) inhibitors of protein synthesis: tetracycline $30 \mu \mathrm{g}$, chloramphenicol $30 \mu \mathrm{g}$, streptomycin $10 \mu \mathrm{g}$, gentamycin $10 \mu \mathrm{g}$, fusidic acid $10 \mu \mathrm{g}$, erythromycin $15 \mu \mathrm{g}$; (iii) inhibitors of nucleic acid synthesis: ciprofloxacin $5 \mu \mathrm{g}$, nalidixic acid $30 \mu \mathrm{g}$. The above antibiotic concentrations are per disc.

\subsection{Antimicrobial Activity}

The antimicrobial activity was determined by the well diffusion assay. The test was carried out according to the method described by Vinderola et al. [27], with slight modification. The lactobacilli isolates were cultured in MRS broth overnight and the pathogens were grown in Brain Heart Infusion (BHI) broth (Oxoid, UK). $200 \mu \mathrm{L}$ of the test pathogens were spread onto the surface of nutrient agar plates. Wells were punctured into the media. $100 \mu \mathrm{L}$ of CFS (cell free supernatant) obtained by centrifugation of the culture at 13,000 rpm for 1 min (using Microcentrifuge MiniSpin ${ }^{\circledR}$, Eppendorf, Hamburg, Germany), and pH adjusted between 6 and 6.4 was added into the wells. The plates were left inside the refrigerator for $30 \mathrm{~min}$ and then incubated at $37^{\circ} \mathrm{C}$ for $24 \mathrm{~h}$. The antimicrobial activity of the lactobacilli was determined in terms of development of inhibition zones around the wells. The pathogens tested included Escherichia coli, L. monocytogenes, Staphylococcus aureus, S. menston and Enterobacter aerogenes.

\subsection{Assessment of Bacterial Hydrophobicity}

The BATH test was employed, to investigate the effect of $\mathrm{pH}$ on the hydrophobic nature of the lactobacilli isolates. The isolates were cultured in MRS broth (pH 6.4) overnight at $37^{\circ} \mathrm{C}$. The cells were 
then centrifuged and washed twice in $1 \times$ phosphate buffered saline. A $20 \mathrm{~mL}$ suspension was prepared and initial optical density (O.D.) adjusted to an absorbance of 1 at $600 \mathrm{~nm}$. In brief, $6 \mathrm{~mL}$ of a suspension of lactobacilli in phosphate buffered saline at $\mathrm{pH} 1.0,5.0$ and 7.4 adjusted with $1 \mathrm{M} \mathrm{HCl}$ was added to $0.7 \mathrm{~mL}$ of organic phase (dichloromethane) in glass test tubes (with a tapered bottom) and then vortexed for $5 \mathrm{~min}$. After equilibration for $15 \mathrm{~min}$ at room temperature $\left(22^{\circ} \mathrm{C}\right)$ to allow for phase separation, $1 \mathrm{~mL}$ of the aqueous phase was transferred to a cuvette without disturbing the organic phase and the O.D. was measured at $600 \mathrm{~nm}$. All experiments were performed in triplicate.

\subsection{Statistical Analysis}

A one-way analysis of variance (ANOVA) was employed, using the program IBM SPSS Statistics (version 21, IBM, Armonk, NY, USA) to evaluate the experimental data for BATH/adherence test. The significant differences were accepted at $p<0.05$ by Duncan's test.

\section{Results}

\subsection{Isolation, Phenotypic Characterization and Carbohydrate Fermentation Profile of Strains}

All isolates appeared as round, opaque, creamy or milky white colonies on the surface of MRS agar. When viewed under the microscope after gram staining, they appeared as purple colour rods, suggesting gram positive bacteria. All isolates showed a negative result when tested for oxidase activity. Glucose, galactose, lactose, melibiose, maltose, raffinose, ribose and sucrose were fermented by all isolates. Isolate RC 25 was however incapable of fermenting arabinose. Dairy isolates (MI 6, MI 7 and MI 10) did not ferment cellobiose, mannose, mannitol and sorbitol. Only two isolates, MI 6 and MI 7, were unable to ferment fructose. All isolates tested negative for glycerol utilization. Rumen isolates displayed better capabilities in comparison to dairy isolates, with regard to utilization of available sugars (Table 1).

\subsection{Identification of $L A B$}

Agarose gel electrophoresis identified DNA bands corresponding to the primers 16-1A and 23-1B. Sequence comparison using BLASTN nucleotide database from the National Center for Biotechnology Information (NCBI) (confirmed that all isolates belonged to species of Lactobacillus (Table 2).

\subsection{Acid Tolerance}

At $\mathrm{pH} 2$, the viability of isolates decreased after $6 \mathrm{~h}$, with bacterial isolates MI 13 and MI 17 recording total absence of growth. Dairy isolate, MI 10 recorded maximum tolerance to $\mathrm{pH} 2$ even after an exposure of $6 \mathrm{~h}$. However, with $\mathrm{pH} 3$, the viability was constant in all isolates even after $6 \mathrm{~h}$ (Figure 1). Overall, the dairy isolates recorded a slightly increased tolerance to acidic environment, in comparison to rumen isolates. 
Table 1. Sugar fermentation capacity of each strain.

\begin{tabular}{|c|c|c|c|c|c|c|c|c|c|c|c|c|c|c|c|c|}
\hline Strain & Source & Arabinose & Cellobiose & Fructose & Glucose & Galactose & Glycerol & Lactose & Mannose & Mannitol & Melibiose & Maltose & Raffinose & Ribose & Sorbitol & Sucrose \\
\hline MI 6 & $\begin{array}{l}\text { dairy } \\
\text { food }\end{array}$ & ++ & - & - & ++ & ++ & - & ++ & - & - & ++ & ++ & ++ & + & - & ++ \\
\hline MI 7 & $\begin{array}{l}\text { dairy } \\
\text { food }\end{array}$ & ++ & - & - & ++ & ++ & - & ++ & - & - & ++ & ++ & ++ & + & - & ++ \\
\hline MI 10 & $\begin{array}{l}\text { dairy } \\
\text { food }\end{array}$ & ++ & - & + & ++ & ++ & - & ++ & - & - & ++ & ++ & ++ & + & - & ++ \\
\hline MI 13 & $\begin{array}{l}\text { dairy } \\
\text { food }\end{array}$ & ++ & ++ & ++ & ++ & ++ & - & ++ & ++ & ++ & ++ & ++ & ++ & ++ & + & ++ \\
\hline MI 17 & $\begin{array}{l}\text { dairy } \\
\text { food }\end{array}$ & ++ & ++ & ++ & ++ & ++ & - & ++ & ++ & ++ & ++ & ++ & ++ & ++ & ++ & ++ \\
\hline $\mathrm{RC} 2$ & $\begin{array}{l}\text { animal } \\
\text { rumen }\end{array}$ & ++ & ++ & ++ & ++ & ++ & - & ++ & ++ & ++ & ++ & ++ & ++ & ++ & ++ & ++ \\
\hline RC 5 & $\begin{array}{l}\text { animal } \\
\text { rumen }\end{array}$ & ++ & ++ & ++ & ++ & ++ & - & ++ & ++ & ++ & ++ & ++ & ++ & ++ & ++ & ++ \\
\hline $\mathrm{RC} 13$ & $\begin{array}{l}\text { animal } \\
\text { rumen }\end{array}$ & ++ & ++ & ++ & ++ & ++ & - & ++ & ++ & ++ & ++ & ++ & ++ & ++ & ++ & ++ \\
\hline $\mathrm{RC} 25$ & $\begin{array}{l}\text { animal } \\
\text { rumen }\end{array}$ & - & ++ & ++ & ++ & ++ & - & ++ & ++ & ++ & ++ & ++ & ++ & ++ & ++ & ++ \\
\hline $\mathrm{RC} 30$ & $\begin{array}{l}\text { animal } \\
\text { rumen }\end{array}$ & ++ & ++ & ++ & ++ & ++ & - & ++ & ++ & ++ & ++ & ++ & + & + & ++ & ++ \\
\hline
\end{tabular}


Table 2. Strain identification.

\begin{tabular}{cccc}
\hline Sl. No & Microbial ID & Source & Genetic Identification \\
\hline 1 & MI 6 & $\begin{array}{c}\text { dairy food } \\
\text { (yoghurt) }\end{array}$ & Lactobacillus reuteri TD1, complete genome \\
\hline 2 & MI 7 & $\begin{array}{c}\text { dairy food } \\
\text { (yoghurt) }\end{array}$ & Lactobacillus reuteri JCM 1112 DNA, complete genome \\
\hline 3 & MI 10 & $\begin{array}{c}\text { dairy food } \\
\text { (yoghurt) }\end{array}$ & Lactobacillus reuteri strain C16 \\
\hline 4 & MI 13 & $\begin{array}{c}\text { dairy food } \\
\text { (cheese) }\end{array}$ & Lactobacillus rhamnosus LOCK 908, complete genome \\
\hline 5 & MI 17 & $\begin{array}{c}\text { dairy food } \\
\text { (cheese) }\end{array}$ & Lactobacillus rhamnosus LOCK 908, complete genome \\
\hline 7 & RC 2 & $\begin{array}{c}\text { animal rumen } \\
\text { (cow) }\end{array}$ & Lactobacillus plantarum 16, complete genome \\
\hline 8 & RC 5 & $\begin{array}{c}\text { animal rumen } \\
\text { (cow) }\end{array}$ & Lactobacillus plantarum 16, complete genome \\
\hline 9 & RC 13 & $\begin{array}{c}\text { animal rumen } \\
\text { (cow) }\end{array}$ & Lactobacillus plantarum subsp. plantarum ST-III, complete genome \\
\hline 10 & RC 25 30 & $\begin{array}{c}\text { animal rumen } \\
\text { (cow) }\end{array}$ & $\begin{array}{c}\text { Lactobacillus plantarum 16, complete genome } \\
\text { (cow) }\end{array}$ \\
\hline
\end{tabular}

\subsection{Bile Salt Tolerance}

Rumen isolate RC 25, in particular demonstrated the highest tolerance to $2 \%$ of bile salts even after $6 \mathrm{~h}$. On the other hand, dairy isolate MI 13 exhibited the least tolerance after a $6 \mathrm{~h}$ period. In general the rumen isolates however, showed a greater tolerance to bile salts after $6 \mathrm{~h}$ in comparison to dairy isolates (Table 3).

Table 3. Strain viability after 0,3 and $6 \mathrm{~h}$ incubation in $0.3 \%$ or $2 \%$ bile salts.

\begin{tabular}{|c|c|c|c|c|c|c|c|}
\hline \multirow{2}{*}{ Strain } & \multirow{2}{*}{ Source } & \multicolumn{3}{|c|}{$0.3 \%$ Bile } & \multicolumn{3}{|c|}{$2 \%$ Bile } \\
\hline & & $\mathbf{O} \mathbf{h}$ & $3 \mathbf{h}$ & $6 \mathrm{~h}$ & $\mathbf{O} \mathbf{h}$ & $3 \mathbf{h}$ & $6 \mathrm{~h}$ \\
\hline MI 6 & dairy food & $9.794 \pm 0.054$ & $8.016 \pm 0.088$ & $8.777 \pm 0.087$ & $9.658 \pm 0.007$ & $9.078 \pm 0.051$ & $9.078 \pm 0.051$ \\
\hline MI 7 & dairy food & $10.021 \pm 0.012$ & $8.574 \pm 0.008$ & $8.562 \pm 0.008$ & $10.158 \pm 0.013$ & $8.889 \pm 0.157$ & $9.230 \pm 0$ \\
\hline MI 10 & dairy food & $9.602 \pm 0$ & $8.984 \pm 0.003$ & $8.469 \pm 0.031$ & $9.511 \pm 0.113$ & $9.102 \pm 0.144$ & $8.778 \pm 0.249$ \\
\hline MI 13 & dairy food & $9.451 \pm 0.213$ & $8.067 \pm 0.021$ & $9.434 \pm 0.025$ & $7.827 \pm 0.181$ & $8.661 \pm 0.260$ & $7.389 \pm 0.125$ \\
\hline MI 17 & dairy food & $8.866 \pm 0.125$ & $9.075 \pm 0.010$ & $8.396 \pm 0.049$ & $8.651 \pm 0.069$ & $8.540 \pm 0.088$ & $7.500 \pm 0.281$ \\
\hline $\mathrm{RC} 2$ & animal rumen & $9.217 \pm 0.019$ & $9.428 \pm 0.017$ & $9.477 \pm 0$ & $8.923 \pm 0.110$ & $9.289 \pm 0.047$ & $9.755 \pm 0.043$ \\
\hline RC 5 & animal rumen & $10.069 \pm 0.013$ & $9.041 \pm 0.017$ & $9.477 \pm 0$ & $10.234 \pm 0.009$ & $9.136 \pm 0.134$ & $9.581 \pm 0.088$ \\
\hline $\mathrm{RC} 13$ & animal rumen & $9.413 \pm 0.047$ & $9.118 \pm 0.012$ & $9.346 \pm 0.008$ & $9.802 \pm 0.044$ & $8.690 \pm 0.125$ & $9.711 \pm 0.042$ \\
\hline $\mathrm{RC} 25$ & animal rumen & $8.922 \pm 0.110$ & $8.841 \pm 0.013$ & $9.477 \pm 0$ & $9.589 \pm 0.063$ & $9.300 \pm 0.031$ & $9.920 \pm 0.048$ \\
\hline RC 30 & animal rumen & $9.096 \pm 0.025$ & $8.679 \pm 0.051$ & $9.229 \pm 0.033$ & $9.871 \pm 0.037$ & $9.918 \pm 0.052$ & $9.590 \pm 0.032$ \\
\hline
\end{tabular}

Presented values are means of duplicate determinations. \pm indicates standard deviation from the mean. 


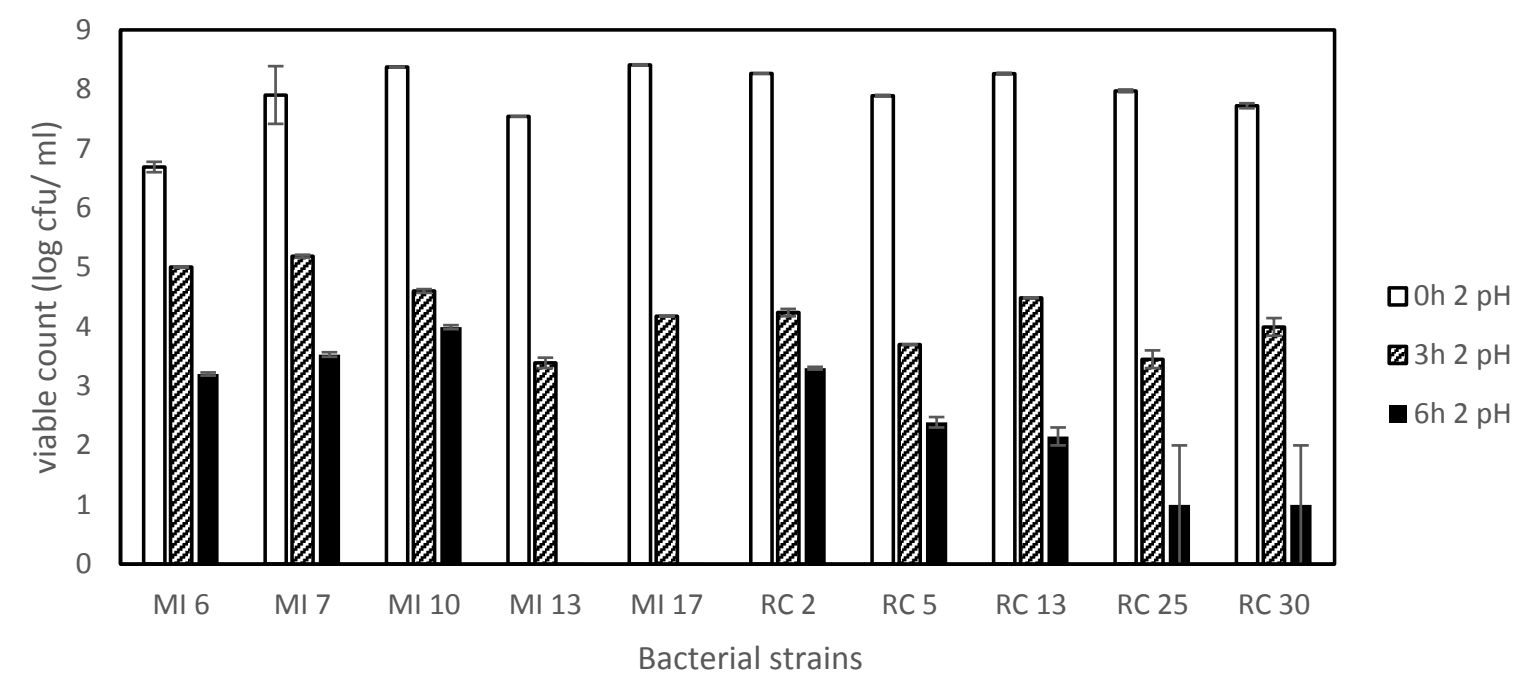

(A)

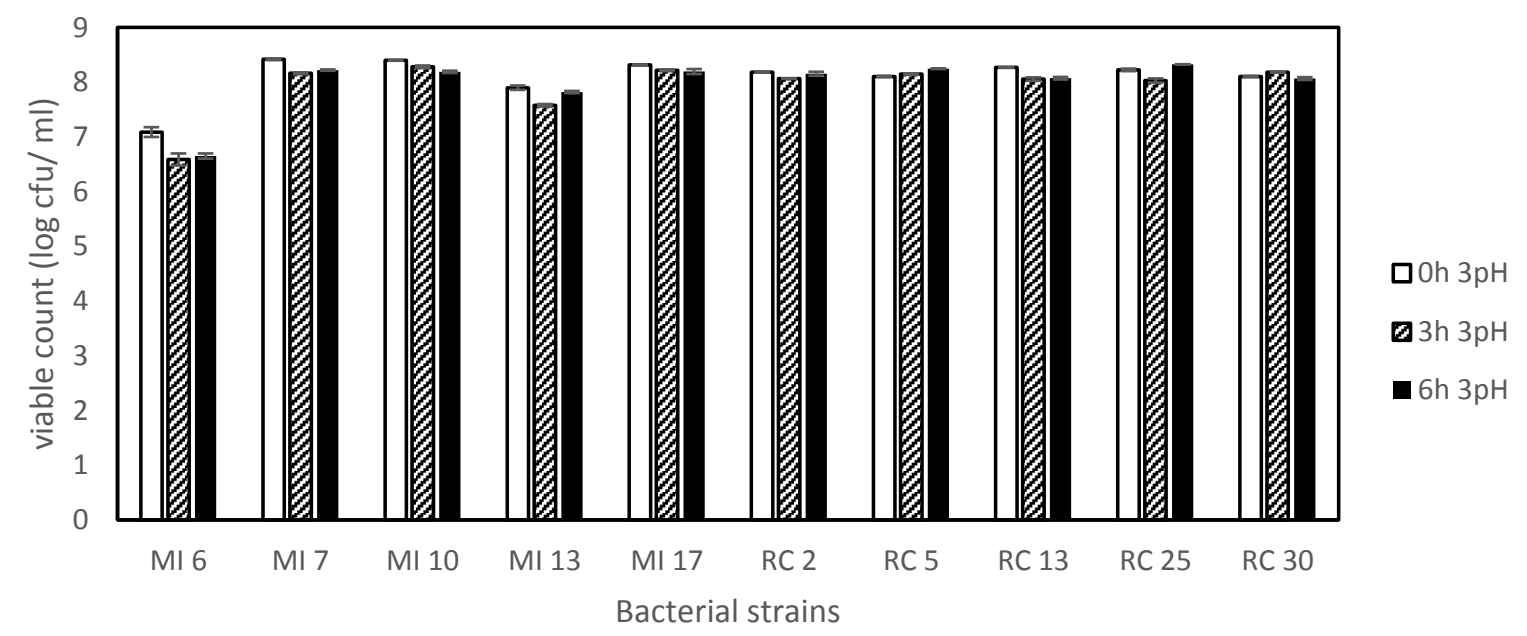

(B)

Figure 1. Viability of the strains expressed as $\log \mathrm{cfu} / \mathrm{mL}$ after 0,3 and $6 \mathrm{~h}$ incubation at pH 2 (A) and $\mathrm{pH} 3$ (B).

\subsection{Haemolytic Activity}

All ten lactobacilli isolates tested negative for haemolytic activity. The positive controls, L. monocytogenes, exhibited complete haemolysis and S. menston exhibited partial haemolysis (data not shown).

\subsection{Antibiotic Resistance}

The isolates showed $100 \%$ resistance to streptomycin, gentamycin, ciprofloxacin, vancomycin, kanamycin and nalidixic acid. Four dairy isolates and a rumen isolate showed resistance to tetracycline, four rumen isolates showed intermediate resistance and one dairy isolate was susceptible to the tetracycline. Three dairy isolates were resistant to erythromycin, five rumen isolates and one dairy isolate showed intermediate resistance and one dairy isolate was susceptible to the erythromycin. Maximum 
susceptibility was observed with chloramphenicol and ampicillin with all rumen and two dairy isolates being susceptible and three dairy isolates showing resistance (Table 4). In general dairy isolates exhibited a better antibiotic resistance profile than rumen isolates.

Table 4. Strain antibiotic resistance profile against various antibiotics tested.

\begin{tabular}{|c|c|c|c|c|c|c|c|c|c|c|c|c|}
\hline \multirow{2}{*}{ Strain } & \multirow{2}{*}{ Source } & \multicolumn{11}{|c|}{ Antibiotic Resistance * } \\
\hline & & TE & ST & NA & $\mathbf{C N}$ & FA & VA & $\mathbf{K}$ & $\mathbf{C}$ & $\mathbf{E}$ & CIP & $\overline{\text { AMP }}$ \\
\hline MI 6 & dairy food & $\mathrm{R}$ & $\mathrm{R}$ & $\mathrm{R}$ & $\mathrm{R}$ & $\mathrm{R}$ & $\mathrm{R}$ & $\mathrm{R}$ & $\mathrm{R}$ & $\mathrm{R}$ & $\mathrm{R}$ & $\mathrm{R}$ \\
\hline MI 7 & dairy food & $\mathrm{R}$ & $\mathrm{R}$ & $\mathrm{R}$ & $\mathrm{R}$ & $\mathrm{R}$ & $\mathrm{R}$ & $\mathrm{R}$ & $\mathrm{R}$ & $\mathrm{R}$ & $\mathrm{R}$ & $\mathrm{R}$ \\
\hline MI 10 & dairy food & $\mathrm{R}$ & $\mathrm{R}$ & $\mathrm{R}$ & $\mathrm{R}$ & $\mathrm{R}$ & $\mathrm{R}$ & $\mathrm{R}$ & $\mathrm{R}$ & $\mathrm{R}$ & $\mathrm{R}$ & $\mathrm{R}$ \\
\hline MI 13 & dairy food & $\mathrm{S}$ & $\mathrm{R}$ & $\mathrm{R}$ & $\mathrm{R}$ & $\mathrm{R}$ & $\mathrm{R}$ & $\mathrm{R}$ & $\mathrm{S}$ & $\mathrm{S}$ & $\mathrm{R}$ & S \\
\hline MI 17 & dairy food & $\mathrm{R}$ & $\mathrm{R}$ & $\mathrm{R}$ & $\mathrm{R}$ & $\mathrm{R}$ & $\mathrm{R}$ & $\mathrm{R}$ & $\mathrm{S}$ & I & $\mathrm{R}$ & S \\
\hline $\mathrm{RC} 2$ & animal rumen & $\mathrm{R}$ & $\mathrm{R}$ & $\mathrm{R}$ & $\mathrm{R}$ & $\mathrm{R}$ & $\mathrm{R}$ & $\mathrm{R}$ & $\mathrm{S}$ & I & $\mathrm{R}$ & S \\
\hline $\mathrm{RC} 5$ & animal rumen & I & $\mathrm{R}$ & $\mathrm{R}$ & $\mathrm{R}$ & $\mathrm{R}$ & $\mathrm{R}$ & $\mathrm{R}$ & $\mathrm{S}$ & I & $\mathrm{R}$ & S \\
\hline $\mathrm{RC} 13$ & animal rumen & I & $\mathrm{R}$ & $\mathrm{R}$ & $\mathrm{R}$ & $\mathrm{R}$ & $\mathrm{R}$ & $\mathrm{R}$ & $\mathrm{S}$ & I & $\mathrm{R}$ & S \\
\hline $\mathrm{RC} 25$ & animal rumen & I & $\mathrm{R}$ & $\mathrm{R}$ & $\mathrm{R}$ & $\mathrm{R}$ & $\mathrm{R}$ & $\mathrm{R}$ & $\mathrm{S}$ & I & $\mathrm{R}$ & S \\
\hline $\mathrm{RC} 30$ & animal rumen & I & $\mathrm{R}$ & $\mathrm{R}$ & $\mathrm{R}$ & $\mathrm{R}$ & $\mathrm{R}$ & $\mathrm{R}$ & $\mathrm{S}$ & I & $\mathrm{R}$ & S \\
\hline
\end{tabular}

\subsection{Antimicrobial Activity}

None of the isolates could inhibit the growth of $E$. coli on the nutrient agar plates. Maximum size of inhibition zones was exhibited against L. monocytogenes. A mixed response was seen in case of E. aerogenes, S. aureus and S. menston. Three dairy isolates MI 6, MI 7 and MI 10, did not show any inhibitory effect on Listeria species (Table 5). Rumen isolates portrayed better antimicrobial activity towards the pathogens.

Table 5. Antimicrobial activity profile of strains against various pathogens.

\begin{tabular}{ccccccc}
\hline Strain & Source & $\begin{array}{c}\text { Escherichia } \\
\text { coli }\end{array}$ & $\begin{array}{c}\text { Listeria } \\
\text { monocytogenes }\end{array}$ & $\begin{array}{c}\text { Enterobacter } \\
\text { aerogenes }\end{array}$ & $\begin{array}{c}\text { Staphylococcus } \\
\text { aureus }\end{array}$ & $\begin{array}{c}\text { Salmonella } \\
\text { menston }\end{array}$ \\
\hline MI 6 & dairy food & - & - & + & \pm & + \\
MI 7 & dairy food & - & - & + & + & + \\
MI 10 & dairy food & - & - & + & + & \pm \\
MI 13 & dairy food & - & + & + & + & \pm \\
MI 17 & dairy food & - & ++ & + & + & + \\
RC 2 & animal rumen & - & + & + & - & + \\
RC 5 & animal rumen & - & ++ & + & + & + \\
RC 13 & animal rumen & - & ++ & + & + & + \\
RC 25 & animal rumen & - & ++ & + & + & + \\
RC 30 & animal rumen & - & +++ & + & + \\
\hline
\end{tabular}

Zone of inhibition $<0 \mathrm{~mm}(-), 0-4 \mathrm{~mm}( \pm), 4-8 \mathrm{~mm}(+), 8-12 \mathrm{~mm} \mathrm{(++)}$ and $>12 \mathrm{~mm} \mathrm{(+++)}$. 


\subsection{Bacterial Adherence to Hydrocarbons}

The adsorbence of the lactobacilli isolates to dichloromethane showed an isolate and $\mathrm{pH}$ effect. At lower $\mathrm{pH}$ the rumen isolates were more adsorbent to the dichloromethane. Maximum adherence was exhibited between $\mathrm{pH} 1-\mathrm{pH}$ 5. Rumen isolates $\mathrm{RC} 2$ and $\mathrm{RC} 25$ showed maximum absorbance to dichloromethane (Figure 2).

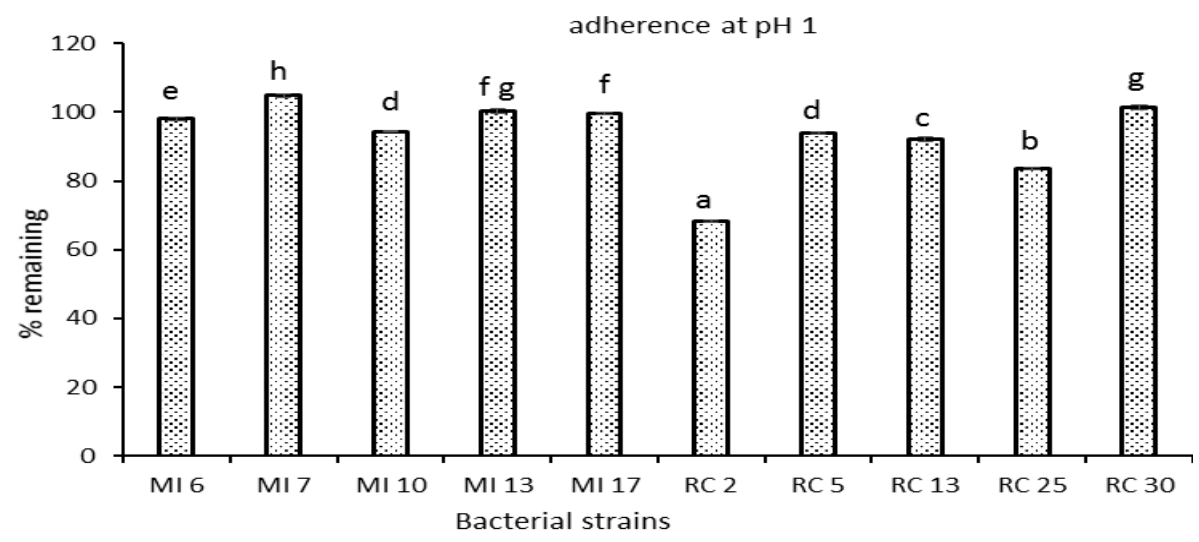

(A)

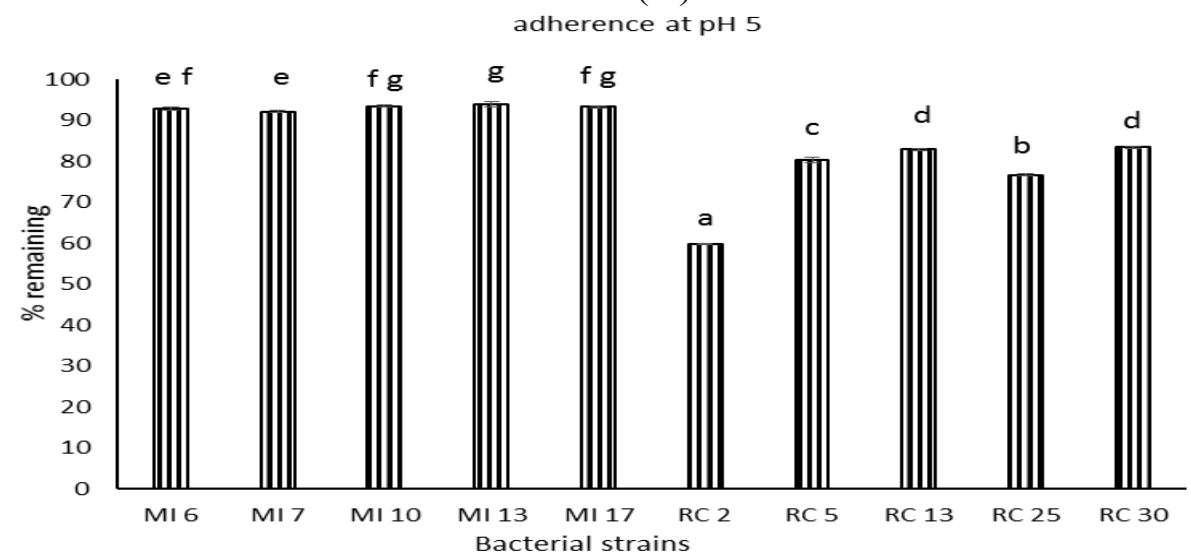

(B)

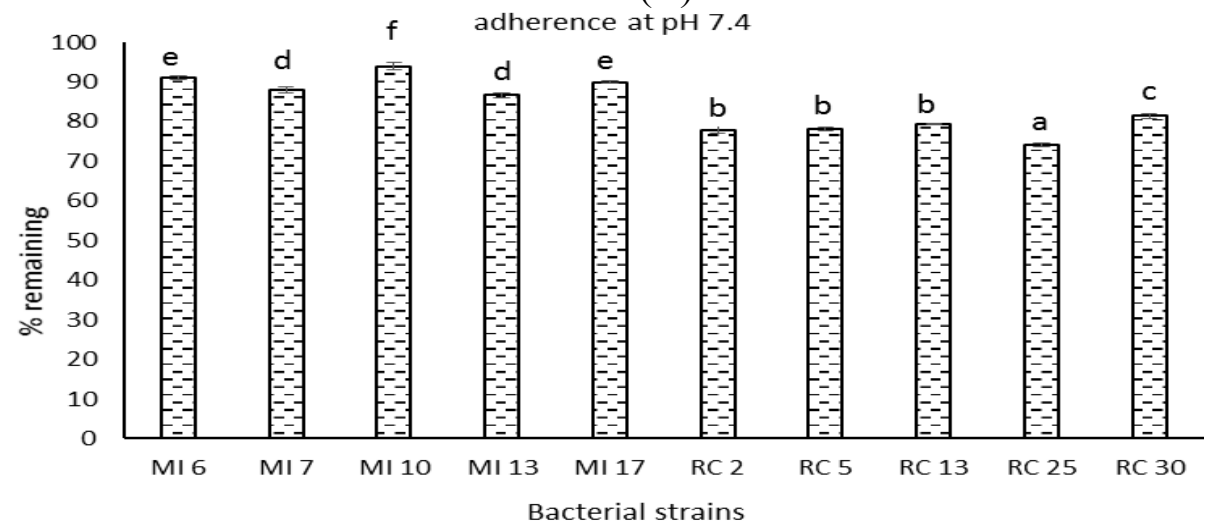

(C)

Figure 2. Percent initial OD at $600 \mathrm{~nm}$ following lactobacilli strains adherence at $\mathrm{pH} 1$ (A); pH 5 (B); and pH $7.4(\mathbf{C})$ to dichloromethane. Standard error of the mean bars $(n=3)$ and columns with different letters for a given $\mathrm{pH}$ differ significantly $(p<0.05)$. 


\section{Discussion}

Screening of lactobacilli from diverse ecological niches for potential probiotic applications has been systematically carried out. However, a comparative profile of lactobacilli from two different ecological niches has not been reported. So, the focus of our study was to test the dairy and rumen isolates under similar challenges and compare their results to see which group of isolates performed better. An ideal animal rumen $\mathrm{pH}$ is 6-7. All rumen isolates are well adapted to grow and survive in the ruminant digestive system where it is exposed to range of stressful conditions in the GIT. However, their challenge would lie in growing under human GIT conditions. Having a common experimental design for dairy and rumen isolates was necessary to compare and interpret their results. Rumen isolates may be exposed to antibiotics through their clinical use as animal health therapeutics. One such example includes a condition known as postpartum metritis in cows. Antibiotics have typically performed poorly when treating this condition however traces of antibiotics can be found in milk [28,29]. This suggests that rumen isolates might from time to time be exposed to therapeutic antibiotic use and it could be expected that possession of non-transferable resistance would be a beneficial characteristic and aid in vivo survival. All the lactobacilli isolates used in this study, which include species-reuteri, rhamnosus and plantarum, are GRAS (Generally Regarded As Safe) according to the New Zealand Agricultural Compounds \& Veterinary Medicines (ACVM) group of the MPI (Ministry for Primary Industries). Till date, there have been no reported incidents of pathogenicity associated with the use of these bacteria [30]. It is expected that the ten isolates used in this study could be used as potential probiotics for humans, poultry or livestock. They can either be incorporated into foods for human consumption, imparting a general overall well-being to the host or they could also be used in animal feed for protection against infections or as growth promoters. In this study, all dairy and rumen isolates were subjected to a range of physiologically applicable stresses and in vitro responses were analysed.

Firstly, the ten isolates used in this study were identified by phenotypic characterization and genotypic methods. After being identified as lactobacilli, they were subjected to screening for potential probiotic abilities. All the isolates proved capable of tolerating low $\mathrm{pH}$ conditions ( $\mathrm{pH} 2$ and $\mathrm{pH} 3$ ). However, viability decreased with a decrease in $\mathrm{pH}$. In similar studies, it was found that the strains could tolerate and survive in MRS broth of $\mathrm{pH} 3$, whereas low viability was observed at $\mathrm{pH} 2$ [31,32]. Bile salt at a concentration of $0.3 \%$ is the maximum that can be found in an average healthy person. Thus, in this study $0.3 \%$ was selected as the starting range for screening the isolates. The result showed that all isolates could tolerate the $0.3 \%$ and $2 \%$ bile salt condition. However, higher tolerance was monitored at $0.3 \%$ concentration of bile salt. Our findings are similar with those reported elsewhere where lactobacilli was found to grow well and multiply in $0.3 \%$ of bile salt [33]. As per safety concerns, a potential probiotic bacteria should not cause lysis of red blood cells in the body. In vitro investigation of this was done by testing the isolates for haemolytic activity; lactobacilli are usually non-haemolytic in nature. All the ten isolates were incapable of exhibiting haemolysis on the agar media containing $5 \%$ sheep blood. This is in agreement with other reports of lactic acid bacteria and bifidobacteria species confirming that they are non-haemolytic in nature [34]. Regarding antibiotic resistance, the isolates showed a mixed response. All ten isolates showed resistance to streptomycin, nalidixic acid, gentamycin, fusidic acid, vancomycin, kanamycin and ciprofloxacin. In case of tetracycline, four dairy isolates (MI 6, MI 7, MI 10, and MI 17) and one rumen isolate ( $\mathrm{RC} 2$ ) showed resistance. One dairy isolate, MI 13, was sensitive to four 
antibiotics. Four rumen isolates, RC 5, RC 13, RC 25 and RC 30, showed intermediate resistance towards the antibiotic. For erythromycin; three dairy isolate (MI 6, MI 7, MI 10) showed high resistance, one dairy isolate, MI 13, was sensitive and remaining six isolates showed intermediate resistance. Maximum susceptibility was observed against chloramphenicol and ampicillin. In some lactobacillus species, such as L. rhamnosus, L. casei, L. plantarum, L. fermentum, L. brevis, and L. curvatus, vancomycin resistance has been reported as an inherent property of the strain that is not re-transferable across species or genus [35]. Thus resistance observed against vancomycin in this study was not unexpected. Previous studies also noted a high resistance to aminoglycosides such as kanamycin, streptomycin and gentamicin amongst lactobacilli $[22,36]$. Likewise previous studies have also reported high resistance to nalidixic acid [7]. Studies have reported that lactobacilli are usually sensitive to ampicillin [37,38]. Innate resistance of probiotics to some antibiotics suggests their use for preventive and therapeutic purposes in controlling intestinal infections especially when co-administered with the therapeutic use of antibiotics. According to the antimicrobial activity data obtained, it was observed that all ten isolates did not inhibit E. coli. Four rumen isolates, RC 5, RC 13, RC 25 and RC 30, were able to inhibit E. aerogenes. Only MI 13 was incapable of inhibiting E. aerogenes. Growth of $S$. aureus was inhibited by MI 7, MI 13, RC 2, RC 25 and RC 30. Rumen isolate RC 5 did not inhibit S. aureus. S. menston inhibition was observed by all five rumen isolates and three dairy isolates, MI 6, MI 7 and MI 17. The highest degree of inhibition was observed against L. monocytogenes, where all five rumen isolates and two dairy isolates MI 13 and MI 17 showed clear inhibition zones. Inhibition of gram-positive bacteria, such as L. monocytogenes and S. aureus, by lactobacillus species has been described previously [20]. We found that rumen isolates tended to inhibit the growth of these pathogens to a greater extent than the isolates form dairy sources. This is perhaps not unexpected, as the rumen isolates would possibly co-exist with these pathogens or at the least have to compete in vivo during incidences of infection by these pathogens of the host form, which the isolates were collected. Rumen isolate RC 2 showed the maximum adherence per cent at $\mathrm{pH} 1$ and $\mathrm{pH} 5$, closely followed by the rumen isolate RC 25. However, at pH $7.4 \mathrm{RC} 25$ showed the highest adherence followed by RC 2 . Overall the data suggests that the dairy isolates had very poor adherence properties in comparison to the rumen isolates. Cell surface hydrophobicity as an indication of potential adherence capabilities is an important characteristic of potential probiotics. Strains with a good adherence property indicate that they might be better capable of binding to the intestinal epithelial lining and improving the cell barrier functions [39]. This mechanism is one of the major factors by which probiotic bacteria are believed to exert beneficial effects in the host.

\section{Conclusions}

In conclusion, this study indicates that isolates of rumen origin exhibited a slightly increased tolerance to adverse stress conditions, especially towards presence of bile salts, inhibition of pathogens and adherence property, in comparison to isolates of dairy origin. This study has provided valuable information on the in vitro characteristics of rumen and dairy isolates, which has helped in the identification of potential probiotic candidates that can be used for further investigation and development as potential probiotics in foods and complementary and alternate medicines. 


\section{Acknowledgments}

This work was funded by the Faculty of Agriculture and Life Sciences, Lincoln University, New Zealand.

\section{Author Contributions}

Neethu Maria Jose conducted laboratory work and drafted this paper as a Ph.D. student. Craig R. Bunt co-supervised the research work, assisted in data interpretation and finalizing article write-up. Malik Hussain played the role of the principal supervisor and responsible for manuscript preparation, data interpretation and all other aspects of the work.

\section{Conflicts of Interest}

The authors declare no conflict of interest.

\section{References}

1. Probiotics Market-Global Industry Analysis, Market Size, Share, Trends, Analysis, Growth and Forecast, 2012-2018. Available online: http://www.transparencymarketresearch.com/ probioticsmarket.html2013 (accessed on 24 October 2014).

2. Felix, G.E.; Dellaglio, F. Taxonomy of lactobacilli and bifidobacteria. Curr. Issues Intest. Microbiol. 2007, 8, 44-61.

3. Isolauri, E. The role of probiotics in paediatrics. Curr. Pediatr. 2004, 14, 104-109.

4. Czerucka, D.; Piche, T.; Rampal, P. Yeast as probiotics-Saccharomyces boulardii. Aliment. Pharmacol. Ther. 2007, 26, 767-778.

5. Gupta, V.; Garg, R. Probiotics. Indian J. Med. Microbiol. 2009, 27, 202-209.

6. Holzapfel, W.H.; Haberer, P.; Geisen, R.; Bjorkroth, J.; Schillinger, U. Taxonomy and important features of probiotic microorganisms in food and nutrition. Am. J. Clin. Nutr. 2001, 73, 365S-373S.

7. Tambekar, D.H.; Bhutada, S.A. An evaluation of probiotic potential of Lactobacillus sp. from milk of domestic animals and commercial available probiotic preparations in prevention of enteric bacterial infections. Recent Res. Sci. Technol. 2010, 2, 82-88.

8. Parvez, S.; Malik, K.A.; Ah Kang, S.; Kim, H.Y. Probiotics and their fermented food products are beneficial for health. J. Appl. Microbiol. 2006, 100, 1171-1185.

9. Mombelli, B.; Gismondo, M.R. The use of probiotics in medical practice. Int. J. Antimicrob. Agents 2000, 16, 531-536.

10. Kailasapathy, K.; Chin, J. Survival and therapeutic potential of probiotic organisms with reference to Lactobacillus acidophilus and Bifidobacterium spp. Immunol. Cell Biol. 2000, 78, 80-88.

11. Kechagia, M.; Basoulis, D.; Konstantopoulou, S.; Dimitriadi, D.; Gyftopoulou, K.; Skarmoutsou, N.; Fakiri, E.M. Health benefits of probiotics: A review. ISRN Nutr. 2013, 2013, doi: $10.5402 / 2013 / 481651$.

12. Musikasang, H.; Tani, A.; H-kittikun, A. Probiotic potential of lactic acid bacteria isolated from chicken gastrointestinal digestive tract. World J. Microbiol. Biotechnol. 2009, 25, 1337-1345. 
13. Shah, N.P. Probiotic bacteria: Selective enumeration and survival in dairy foods. J. Dairy Sci. 2000, 83, 894-907.

14. Chou, L.S.; Weimer, B. Isolation and characterization of acid and bile tolerant isolates from strains of Lactobacillus acidophilus. J. Dairy Sci. 1999, 82, 23-31.

15. Ranadheera, C.S.; Evans, C.A.; Adams, M.C.; Baines, S.K. In vitro analysis of gastrointestinal tolerance and intestinal cell ashesion of probiotics in goat's milk ice cream and yogurt. Food Res. Int. 2012, 49, 619-625.

16. Jose, N.M.; Bunt, C.R.; Hussain, M.A. Implications of antibiotic resistance in probiotics. Food Rev. Int. 2015, 31, 52-62.

17. Alvarez-Olmos, M.I.; Oberhelman, R.A. Probiotic agents and infectious diseases: A modern perspective on a traditional therapy. Clin. Infect. Dis. 2001, 32, 1567-1576.

18. Gueimonde, M.; Salminen, S. New methods for selecting and evaluating probiotics. Dig. Liver Dis. 2006, 38, S242-S247.

19. Suvarna, V.C.; Boby, V.U. Probiotics in human health: A current assessment. Curr. Sci. 2005, 88, 1744-1748.

20. Bao, Y.; Zhang, Y.; Zhang, Y.; Liu, Y.; Wang, S.; Dong, X.; Wang, Y.; Zhang, H. Screening of potential probiotic properties of Lactobacillus fermentum isolated from traditional dairy products. Food Control 2010, 21, 695-701.

21. Guo, X.H.; Kim, J.M.; Nam, H.M.; Park, S.Y.; Kim, J.M. Screening lactic acid bacteria from swine origins for multistrain probiotics based on in vitro functional properties. Anaerobe 2010, 16, 321-326.

22. Kirtzalidou, E.; Pramateftaki, P.; Kotsou, M.; Kyriacou, A. Screening for lactobacilli with probiotic properties in the infant gut microbiota. Anaerobe 2011, 17, 440-443.

23. Zago, M.; Fornasari, M.E.; Carminati, D.; Burns, P.; Suarez, V.; Vinderola, G.; Reinheimer, J.; Giraffa, G. Characterization and probiotic potential of Lactobacillus plantarum strains isolated from cheeses. Food Microbiol. 2011, 28, 1033-1040.

24. Gupta, P.K.; Mital, B.K.; Garg, S.K. Characterization of Lactobacillus acidophilus strains for use as dietary adjunct. Int. J. Food Microbiol. 1996, 29, 105-109.

25. Maragkoudakis, P.A.; Zoumpopoulou, G.; Miaris, C.; Kalantzopoulos, G.; Pot, B.; Tsakalidou, E. Probiotic potential of Lactobacillus strains isolated from dairy products. Int. Dairy J. 2006, 16, 189-199.

26. Thirabunyanon, M.; Boonprasom, P.; Niamsup, P. Probiotic potential of lactic acid bacteria isolated from fermented dairy milks on antiproliferation of colon cancer cells. Biotechnol. Lett. 2009, 31, 571-576.

27. Vinderola, G.; Capellini, B.; Villarreal, F.; Suarez, V.; Quiberoni, A.; Reinheimer, J. Usefulness of a simple set of in vitro tests for the screening and identification of probiotic candidate strains for dairy use. LWT-Food Sci. Technol. 2008, 41, 1678-1688.

28. Abe, F.; Ishibashi, N.; Shimamura, S. Effect of administration of bifidobacteria and lactic acid bacteria to new born calves and piglets. J. Dairy Sci. 1995, 78, 2838-2846.

29. Otero, M.C.; Morelli, L.; Nader-Macias, M.E. Probiotic properties of vaginal lactic acid bacteria to prevent metritis in cattle. Lett. Appl. Microbiol. 2006, 43, 91-97. 
30. Lee, Y.K.; Salminen, S. The coming of age of probiotics. Trends Food Sci. Technol. 1995, 6, 241-245.

31. Liu, X.; Liu, W.; Zhang, Q.; Tian, F.; Wang, G.; Zhang, H.; Chen, W. Screening of lactobacilli with antagonistic activity against enteroinvasive Escherichia coli. Food Control 2013, 30, 563-568.

32. Mishra, V.; Prasad, D.N. Application of in vitro methods for selection of Lactobacillus casei strains as potential probiotics. Int. J. Food Microbiol. 2005, 103, 109-115.

33. Hoque, M.Z.; Akter, F.; Hossain, K.M.; Rahman, M.S.M.; Billah, M.M.; Islam, K.M.D. Isolation, identification and analysis of probiotic properties of Lactobacillus spp. From selective regional yoghurts. World J. Dairy Food Sci. 2010, 5, 39-46.

34. Santini, C.; Baffoni, L.; Gaggia, F.; Granata, M.; Gasbarri, R.; di Gioia, D.; Biavati, B. Characterization of probiotic strains: An application as feed additives in poultry against Campylobacter jejuni. Int. J. Food Microbiol. 2010, 141, S98-S108.

35. D’Aimmo, M.R.; Modesto, M.; Biavati, B. Antibiotic resistance of lactic acid bacteria and Bifidobacterium spp. isolated from dairy and pharmaceutical products. Int. J. Food Microbiol. 2007, $115,35-42$.

36. Fukao, M.; Yajima, N. Assessment of antibiotic resistance in probiotic lactobacilli. In Antibiotic Resistant Bacteria - A Continuous Challenge in the New Millennium; InTech: Rijeka, Croatia, 2012; pp. 503-512.

37. Ammor, M.S.; Florez, A.B.; Mayo, B. Antibiotic resistance in non-enterococcal lactic acid bacteria and bifidobacteria. Food Microbiol. 2007, 24, 559-570.

38. Gueimonde, M.; Sanchez, B.; de los Reyes-Gavilan, C.G.; Margolles, A. Antibiotic resistance in probiotic bacteria. Front. Microbiol. 2013, 202, 1-6.

39. Resta-Lenert, S.; Barrett, K.E. Live probiotics protect intestinal epithelial cells from the effects of infection with enteroinvasive Escherichia coli. Gut 2003, 52, 988-997.

(C) 2015 by the authors; licensee MDPI, Basel, Switzerland. This article is an open access article distributed under the terms and conditions of the Creative Commons Attribution license (http://creativecommons.org/licenses/by/4.0/). 